\title{
AMENDMENTS
}

\section{Author Correction: The reference genome of Miscanthus floridulus illuminates the evolution of Saccharinae}

Guobin Zhang, Chunxia Ge, Pingping Xu, Shukai Wang, Senan Cheng, Yanbin Han, Yancui Wang, Yongbin Zhuang, Xinwei Hou, Ting Yu, Xitong Xu, Shuhan Deng, Quanquan Li, Yinqing Yang, Xiaoru Yin, Weidong Wang, Wenxue Liu, Chunxiao Zheng, Xuezhen Sun, Zhenlin Wang, Ray Ming $\mathbb{D}^{\mathbb{D}}$, Shuting Dong, Jianxin Ma $\mathbb{D}$, Xiansheng Zhang and Cuixia Chen (D)

Correction to: Nature Plants https://doi.org/10.1038/s41477-021-00908-y, published online 6 May 2021.

In Fig. $5 c$ of this Article originally published, the Miscanthus accession names listed along the $x$ axis were outdated. They have now been updated to match the accession names shown in Supplementary Table 12 and Fig. 5b, and the corrected panel is shown below.
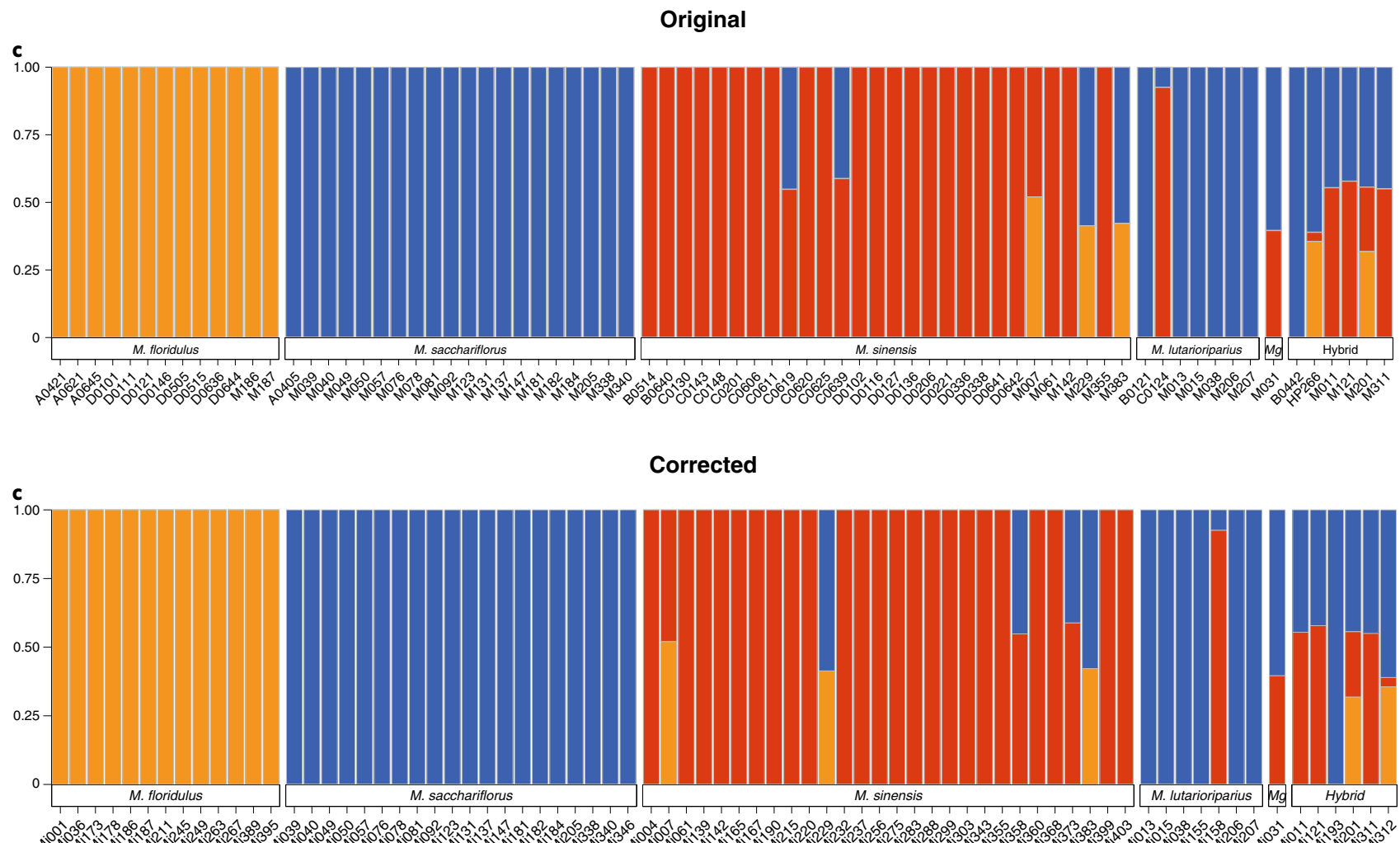

Fig. 5c | Original and Corrected.

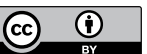

Open Access This article is licensed under a Creative Commons Attribution 4.0 International License, which permits use, sharing, adaptation, distribution and reproduction in any medium or format, as long as you give appropriate credit to the original author(s) and the source, provide a link to the Creative Commons license, and indicate if changes were made. The images or other third party material in this article are included in the article's Creative Commons license, unless indicated otherwise in a credit line to the material. If material is not included in the article's Creative Commons license and your intended use is not permitted by statutory regulation or exceeds the permitted use, you will need to obtain permission directly from the copyright holder. To view a copy of this license, visit http://creativecommons.org/licenses/ by $/ 4.0 \%$.

Published online: 28 June 2021

https://doi.org/10.1038/s41477-021-00972-4

(c) The Author(s) 2021 